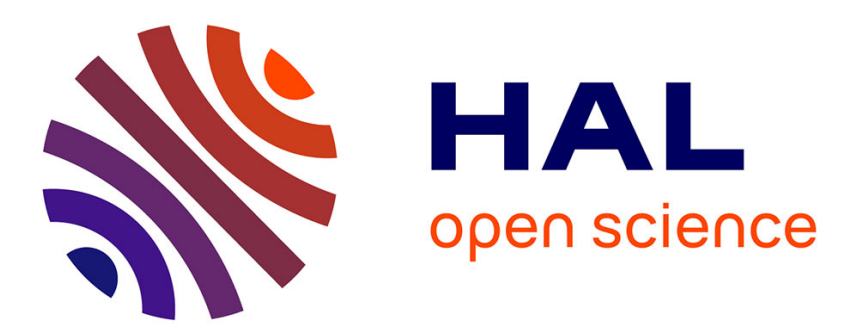

\title{
Distributional effects of road pricing: Assessment of nine scenarios for Paris
}

\author{
Benjamin Bureau, Matthieu Glachant
}

\section{To cite this version:}

Benjamin Bureau, Matthieu Glachant. Distributional effects of road pricing: Assessment of nine scenarios for Paris. Transportation Research Part A: Policy and Practice, 2008, 42 (07), pp.994-1007. 10.1016/j.tra.2008.02.001 . hal-00437759

\section{HAL Id: hal-00437759}

https://hal-mines-paristech.archives-ouvertes.fr/hal-00437759

Submitted on 12 Jan 2010

HAL is a multi-disciplinary open access archive for the deposit and dissemination of scientific research documents, whether they are published or not. The documents may come from teaching and research institutions in France or abroad, or from public or private research centers.
L'archive ouverte pluridisciplinaire HAL, est destinée au dépôt et à la diffusion de documents scientifiques de niveau recherche, publiés ou non, émanant des établissements d'enseignement et de recherche français ou étrangers, des laboratoires publics ou privés. 


\title{
Distributional Effects of Road Pricing: Assessment of Nine Scenarios for Paris
}

\author{
Benjamin Bureau and Matthieu Glachant ${ }^{*}$ \\ Ecole des Mines de Paris, CERNA, 60 boulevard Saint Michel, 75272 Paris Cedex 06, France
}

* Corresponding author. Matthieu Glachant, Ecole des Mines de Paris, CERNA, 60 boulevard Saint Michel, 75272 Paris Cedex 06, France. Tel.: + 33 (0) 1405192 29. Fax: +33 (0)1 4051 91 34. E-mail: glachant@ensmp.fr

Other author’s e-mail address: bureau@ensmp.fr

November 5, 2007 


\begin{abstract}
The starting point of this paper is to consider that there is no general answer to the question of the equity of urban road pricing. We therefore simulate and compare the distributional effects on commuters of nine toll scenarios for Paris, assuming that utility is nonlinear in income. We show that the distributional pattern across income groups depends crucially on the level of traffic reduction induced by tolling. Stringent tolls are more favourable to low-income motorists. Equity effects also vary with toll design. Compared to a reference scenario which uniformly charges all motorists driving within Paris, an inbound cordon toll is detrimental to low-incomes. Conversely, granting a rebate to low CO2 emission cars slightly improves their situation while an exemption for Paris residents is neutral. Surprisingly, it matters little for social equity whether toll revenues are allocated to all commuters or solely to public transport users.
\end{abstract}

Keywords: Road pricing, Distributional effects, Income effects, Equity. 


\section{Introduction}

The success of the London congestion charging scheme, set up in February 2003, has modified the views of many European policymakers on road pricing. Most of them now consider that it is a credible instrument to tackle urban congestion, although the legal framework in some EU countries still prohibits its implementation (e.g., France). However, many stakeholders criticise urban tolls on equity grounds, arguing that it disproportionately burdens low-income travellers. This argument has some theoretical foundations as high-income travellers have generally higher values of travel time than low-income ones. Accordingly, they tend to value more the reduced travel times induced by the implementation of tolls. Furthermore, they value less the financial loss of the toll as the marginal utility of income is decreasing.

Arguments leading to opposite conclusions are also available. For instance, motorists usually have higher incomes than the other travellers. ${ }^{1}$ Most importantly, the overall distributional impacts of road pricing ultimately depend on the allocation of the toll revenues. To sum up, the answer to the question of urban tolls' equity is indeterminate in general. It depends on the scheme considered, on the use of the toll revenues, and on the urban context in which tolling is introduced. Accordingly, the relevant approach consists in comparing the distributional effects of different toll scenarios.

This paper analyzes nine scenarios for Paris using disaggregated data from the Global Transport Survey carried out in 2001-2002 (Enquête Globale Transport Ile-de-France 20012002). The reference scenario is a toll requiring vehicles driven within Paris to pay a uniform fee per trip which induces a 20\% traffic reduction. Then, we consider several variants: different levels of traffic reduction (10\%, 30\% and 50\%); a cordon toll which only applies to vehicles

\footnotetext{
${ }^{1}$ For instance, the income of motorists circulating in Paris is 30\% higher than the income of individuals using PT (source: EGT 2001-2002).
} 
entering Paris, a toll in which residents are partially exempted, a toll with discounts for low CO2 emitting cars. We also study two scenarios of revenue recycling.

We restrict the analysis to commuters and to the direct effects of road pricing: the monetary cost of the toll and the changes in travel time. We derive three indicators reflecting the distributional properties of the scenarios. First, we measure the mean commuters' compensating variation due to the introduction of the toll. In this way, we try to work out the degree of political acceptability of the different scenarios. Second, we characterize the relationship between individual compensating variations, expressed in euros per trip, and income. The aim is to identify the magnitude of the potential redistribution between income groups. Third, we study the relationship between the individual compensating variations, expressed as a percentage of income, and income. The last indicator is usually referred to as regressiveness in public economics.

The empirical literature dealing with the distributional effects of road pricing is developing very quickly. Eliasson and Mattsson (2006) examine the equity effects of a cordon toll in Stockholm. ${ }^{2}$ Teubel (2000) does the same in Dresden, while Santos and Rojey (2004) assess the potential distributional impacts of a cordon toll in three English towns (Cambridge, Northampton and Bedford). Franklin (2006) analyses the equity effects of a toll bridge in the State of Washington, USA. Raux and Souche (2004) examine the distributional effects of an urban toll motorway in Lyon. These five studies analyse a particular form of urban pricing: a bridge toll in Franklin (2006), a link toll on a ring road in Raux and Souche (2004), and a simple inbound cordon toll in the other studies. The results that they give are only valid for the studied scenarios.

In contrast with these papers, we compare nine scenarios. We believe that a comparative approach is better-suited to derive policy implications. By considering different

\footnotetext{
${ }^{2}$ Their scenario is a modified version of the scheme actually implemented in Stockholm in 2006. Note that they analyze different allocations of toll revenues.
} 
variants, we are able to investigate the drivers of the distributional impacts. In this regards, our paper is closer to Safirova et al. (2003), or to Maruyama and Sumalee (2007) who examine different forms of road pricing in Washington, DC. and in Utsunomiya, Japan, respectively. However, their results are not easily transferable to European cities as the geography of urban areas, the spatial distribution of income and the relative importance of public transport (PT hereafter) are completely different. In particular, Safirova et al.'s results depend crucially on the pre-existence of restricted high-occupancy vehicles (HOV) lanes on major freeways in the DC area. Such HOV lanes hardly ever exist in European cities.

From a methodological point of view, we use a random utility model that is nonlinear in income. This leads us to calculate exact compensating variations for each commuter using the formula recently derived by Dagsvik and Karlström (2005). This is of most interest since, as argued by Jara-Díaz and Videla (1989), traditional mode choice models which assume a constant marginal utility of income tend to under-estimate regressiveness. To the best of our knowledge, Franklin (2006) is the only other work which implements this new method to the equity of urban tolls.

The paper is organized as follows. The first section presents the mode choice model which will provide the basis for the econometric estimations. The second section deals with econometric aspects and the third section presents the results. The last section concludes.

\section{An income-sensitive mode choice model}

In this section, we develop a random-utility model describing the mode choice of individuals making trips which is not linear in income and describe how we calculate individual compensating variations induced by tolling. 
Consider a population of individuals who are forced to make a trip, for example to go to work or to University. This assumption will lead us to make our estimations on a sample of individuals doing home-to-work trips. An individual faces two alternatives $j=A, B$. $A$ describes the option "take the car" and $B$ the option "use PT". The generalised costs associated with the two alternatives are

$$
\begin{aligned}
& \Gamma_{A}=\Omega_{A}+\varepsilon_{A} \\
& \Gamma_{B}=\Omega_{B}+\varepsilon_{B}
\end{aligned}
$$

where $\varepsilon_{A}$ and $\varepsilon_{B}$ are random variables whose realization is only known to the individual. In order to address income effects, we consider a model which is not linear in income. More specifically, assuming budget exhaustion, we write

$$
\begin{aligned}
& \Omega_{A}^{\alpha}=\beta T_{A}^{\alpha}+\gamma \sqrt{y-C_{A}^{\alpha}}+\phi \mathbf{X}+\varphi \mathbf{Y}_{\mathbf{A}} \\
& \Omega_{B}=\beta T_{B}+\gamma \sqrt{y-C_{B}}+\phi \mathbf{X}+\varphi \mathbf{Y}_{\mathbf{B}}
\end{aligned}
$$

with:

$\alpha$ : a superscript equal to 1 if a toll is introduced, 0 otherwise.

$T_{j}$ : the duration of the trip with alternative $j$.

$C_{j}$ : the monetary cost of alternative $j$.

$y$ : the individual's income.

$\mathbf{X}$ : a vector of characteristics of the individual.

$\mathbf{Y}_{\mathbf{j}}$ : a vector of characteristics of the alternative $j$.

$\beta, \gamma, \phi, \varphi$ : the parameters or the vectors of parameters to be estimated.

Note that the duration of the trip by car, $T_{A}$, and the cost $C_{A}$ depend on $\alpha$ as the toll reduces congestion and increases the monetary cost of this alternative. But we assume that the duration of the trip by PT, $T_{B}$, is not affected by the introduction of the toll. This assumption is 
clearly restrictive for trips made by bus that also benefit from the congestion reduction. These trips represent solely $9 \%$ of the trips made by PT in our sample.

Interestingly, the marginal utility of income is not constant under specification (2) as it writes

$$
-\frac{\partial \Omega_{j}}{\partial y}=-\frac{\gamma}{2 \sqrt{y-C_{j}}},
$$

Assuming that $\gamma$ is negative - meaning that the generalised cost of alternative $j$ increases with the monetary cost of $j$ - the marginal utility of income decreases with income. Similarly, the unit value of time is

$$
\lambda_{j} \equiv \frac{\partial \Omega_{j} / \partial T_{j}}{\partial \Omega_{j} / \partial C_{j}}=-2 \frac{\beta}{\gamma} \sqrt{y-C_{j}}
$$

If one realistically assumes that $\gamma<0$ and $\beta>0$, the value of time increases with income.

Before proceeding, let us discuss further assumptions underlying (2). To begin with, (2) implies that a motorist facing a toll has only two options: to continue to use a car or to switch to PT. Hence, we forego at least three other possibilities: (i) to refrain from doing the trip, (ii) to modify the departure time and (iii) to change the route to avoid tolling. To dismiss the first option does not raise particular difficulties because we estimate the mode choice of individuals making home-to-work trips. The second alternative is not very relevant in our case for two reasons. First, we concentrate on home-to-work trips which are not very flexible. Second, this option would be interesting if modifying the departure time permitted to avoid or to reduce the toll payment. But we will not study any scenarios involving a time-varying toll. To neglect the third option is probably more problematic. Studying this option would require a sophisticated traffic model. However, it is only relevant for the trips through Paris; those trips represent a mere $15 \%$ of the trips in our sample. 
Turning next to the calculations of individual surpluses, let $U$ denote the individual's utility. As the individual opts for the least-costly alternative, it is given by:

$$
U(\alpha) \equiv \max \left\{-\Gamma_{A}(\alpha),-\Gamma_{B}\right\}
$$

Consider now a change from the initial state without toll $(\alpha=0)$ to the new state with a toll $(\alpha=1)$. The individual's compensating variation is the amount of money $c v$ such that

$$
U(\alpha=0)=\max \left\{-\left[\beta T_{A}^{1}+\gamma \sqrt{y-c v-C_{A}^{1}}+\phi \mathbf{X}+\varphi \mathbf{Y}_{\mathbf{A}}+\varepsilon_{A}\right],-\left[\beta T_{B}+\gamma \sqrt{y-c v-C_{B}}+\phi \mathbf{X}+\varphi \mathbf{Y}_{\mathbf{B}}+\varepsilon_{B}\right]\right\}
$$

This expression simply says that $c v$ is the amount of money that, when subtracted from income in the new state, equates maximum utility in the new state with maximum utility in the initial state. In this context, compensating variations also vary as a function of income, as one would expect.

The problem is that $U$ is observed by the individual but not by the researcher who can only calculate $E[c v]$. Let us now adopt the researcher's perspective. We consider a traditional logit model in which the probability that individual prefers the car is

$$
\mathrm{P}_{A}=\operatorname{Pr}\left(\Omega_{A}^{\alpha}+\varepsilon_{A}<\Omega_{B}+\varepsilon_{B}\right)=\operatorname{Pr}\left(\varepsilon_{A}-\varepsilon_{B}<\Omega_{B}-\Omega_{A}^{\alpha}\right)
$$

where $\varepsilon_{A}-\varepsilon_{B}$ follows a logistic distribution while the functional form of $\mathrm{P}_{A}$ is given by

$$
\mathrm{P}_{A}\left(\Omega_{A}^{\alpha}, \Omega_{B}\right)=\frac{e^{-\Omega_{A}^{\alpha}}}{e^{-\Omega_{A}^{\alpha}}+e^{-\Omega_{B}}}
$$

If $\Omega_{j}^{\alpha}$ was linear in income, one would simply use the well-known log sum formula to calculate $E[c v]$. However, the presence of income effects makes the calculation much more 
complex. Fortunately, Dagsvik and Karlström (2005) have recently provided an exact formula for the expected compensating variation. ${ }^{3}$ It writes:

$$
E[c v]=y-\sum_{j}\left\{\mu_{j} P_{j}\left(\mu_{j}\right)-\int_{\underline{\mu}}^{\mu_{j}} z \cdot d P_{j}(z)\right\}
$$

where $P_{j}(z)$ is the choice probability:

$$
P_{j}(z)= \begin{cases}P_{A}\left(\Omega_{A}^{0}(y), g_{B}(z)\right) & \text { if } j=A \\ P_{B}\left(g_{A}(z), \Omega_{B}(y)\right) & \text { if } j=B\end{cases}
$$

and

$\mu_{j}$ is implicitly defined by $\Omega_{j}^{0}\left(y, T_{j}^{0}, C_{j}^{0}\right)=\Omega_{j}^{1}\left(\mu_{j}, T_{j}^{1}, C_{j}^{1}\right)$

$$
\begin{aligned}
& \underline{\mu}=\min \left\{\mu_{A}, \mu_{B}\right\} \\
& g_{j}(z)=\max \left[\Omega_{j}^{0}(y), \Omega_{j}^{1}(z)\right]
\end{aligned}
$$

\section{Simulation model and data description}

Having described how we model mode choice and calculate compensating variations $(c v)$, we now describe how we simulate the different toll scenarios.

\subsection{Simulation procedures}

We proceed in five stages.

- We estimate econometrically the parameters $\beta, \gamma, \phi$, and $\varphi$ of equation (2) using data from the 2001-2002 Global Transport Survey.

\footnotetext{
${ }^{3}$ Although an exact formula was not previously available, less satisfactory approximations of E[cv] had been suggested in the literature. For instance, McFadden (1999) has developed a Monte Carlo simulator for computing $\mathrm{cv}$ in random utility models which converges to the true distribution of $\mathrm{cv}$.
} 
- We estimate a speed-flow function that links the traffic level to speed in order to calculate the car travel time $T_{A}^{1}$ once a toll is introduced.

- Using an iterative process, we use the estimated parameters $\hat{\beta}, \hat{\gamma}, \hat{\phi}$, and $\hat{\varphi}$ and the estimated travel time $\hat{T}_{A}^{1}$ to predict the mode choice of motorists with and without the toll.

- We use the formula (7) to calculate the individual compensating variations.

\subsection{Data description}

We use disaggregated data from the 2001-2002 Global Transport Survey (Enquête Globale Transport Ile-de-France 2001-2002). This survey has been carried out regularly for 25 years. It allows us to follow and analyse trip patterns in Ile-de-France. Ile-de-France is a vast area of 12,072 sq km and 10.9 millions inhabitants. The city of Paris is only a small part of that area with a surface of $105 \mathrm{sq} \mathrm{km}$ and 2.1 millions inhabitants.

The sample surveyed is representative of the Ile-de-France population with respect to social and geographical characteristics. 10,500 households were surveyed between October 2001 and April 2002. Each member of the household, older than 6, is interviewed about all the trips she/he made the day before the survey. For each trip, a broad variety of data is available, for example: time of departure and arrival, trip purpose, origin, destination and mode(s) used. General household characteristics are also described (e.g., size, location, income) as well as characteristics of each member (e.g., age, sex, profession).

As stated above, our estimations are limited to home-to-work trips. Those trips represent about one third of car and PT trips in Paris intra muros. Moreover, we only consider travellers possessing a driving licence and belonging to a household owning at least one car. We also focus only on trips made by private car or PT. Non-motorised two-wheel or pedestrian 
trips are therefore excluded considering that urban tolls pertain to an alternative "car versus PT”. We also exclude taxi and motorised two-wheel trips as well as trips made by car as a passenger. Concerning home-to-work trips, the latter options are very rarely chosen $(3.6 \%$ on the trips considered). In the end, our estimations are carried out using a sample of 1032 trips.

Finally, we use control variables that are commonly used (see for example Teubel, 2000):

FEMALE $\quad=1$ if the individual is a woman, 0 otherwise;

FREE_PARK = 1 if the individual gets a car park for free at her place of work, 0 otherwise;

TWO_CARS $=1$ if the household owns two cars or more, 0 otherwise;

TWO_KIDS $=1$ if the household has two children or more, 0 otherwise.

Table 1 presents the main descriptive statistics of our sample and the variables used for the estimation. For instance, it can be seen that motorists represent around $29 \%$ of the sample, that on average car trips last 3.79 minutes less than trips by PT and that woman are in a minority (45\%).

\subsection{Estimation of mode choice and unit values of time}

Table 2 presents the results of the mode choice estimation. Coefficients of the model are clearly significant and present signs that are not absurd. For instance, the number of cars in the household and the availability of a car park for free clearly increase the propensity to travel by car.

Recall that our specification allows us to define thoroughly the relationship between income and unit value of time. Table 3 presents these values by quintile of income. Income group 1 includes the 20\% of individuals having the lowest income; quintiles 1 and 2 include the $40 \%$ of individuals having the lowest income, etc. These figures show a strong and positive relationship between income and value of time. 


\subsection{Time savings}

Time savings are calculated using a speed-flow function estimated econometrically on a sample that describes traffic levels and speeds for 19 time slots. For each slot, we calculate the total traffic by car and the average speed of car trips in Paris. The regression of the logarithm of traffic on the average speed presents a R2 of 0.58 and gives the following relationship:

$$
S P E E D=-69.0 \times \ln (T R A F F I C)+877.4
$$

where SPEED is the average speed of car trips in meters per minute in a given slot and TRAFFIC is the total number of trips per $\operatorname{slot}^{4}$.

We use this equation to calculate times savings by making two simplifying assumptions: (i) motorists travelling partially in the charging zone - those whose origin or destination is outside the zone - cover a distance equal to the average of distances covered by motorists that travel exclusively in the charging zone (namely 3,171 meters for Paris intra muros); (ii) the traffic reduction rate induced by tolling equals the traffic reduction rate predicted for motorists making home-to-work trips. This amounts to assuming that all the motorists generally behave like motorists making home-to-work trips. The first hypothesis is necessary as the Global Transport Survey does not describe the length of the part of the trip made in Paris. The second is necessary because we only estimate mode choices for commuters. Additional details are given in the appendix. The appendix also includes a table giving average travel time reductions for all the scenarios.

\footnotetext{
${ }^{4}$ The level of traffic taken into account is the total traffic observed in the Global Transport Survey, i.e., the traffic due to individual trips. It excludes deliveries and freight.
} 


\subsection{Scenarios considered}

Table 4 describes the 9 scenarios. As a benchmark, we use the so-called Zone scenario. It is a toll which charges uniformly for internal trips within Paris, trips in Paris with an origin or a destination in the suburbs and through trips with both an origin and a destination outside Paris ${ }^{5}$. It is calibrated to lead to a $20 \%$ reduction of the whole traffic within the zone (inbound, outbound or internal). Furthermore, we assume no distribution of toll revenues to commuters. Then, we consider different variations of this reference scenario:

- Other levels of traffic reduction $(10 \%, 30 \%, 50 \%)$.

- The introduction of exemptions: the Inbound Cordon scenario in which the toll only applies to vehicles entering Paris; the Residents scenario where people living within the charging zone (i.e., Paris residents) only pay $10 \%$ of the toll level as in London; the Green scenario where drivers of cars emitting less than 180 gCO2 per km get a 50\% rebate.

We also consider two variants of the Zone scenario where toll revenues are redistributed to commuters. In a first scenario (PT funding), revenues are used to cut PT fares. In a second scenario (Uniform Redistribution), each commuter receives a uniform lump sum payment. ${ }^{6}$

In Table 4, we see that the toll unsurprisingly increases with the level of traffic reduction. It also rises when some motorists are partially or totally exempted (Inbound Cordon, Residents or Green) while it is reduced when the toll revenues are used to cut PT fares as shifting to PT becomes less costly. Interestingly, the toll fee increases slightly when the toll revenues are evenly redistributed to all commuters (Uniform Redistribution). This is a simple income effect: redistribution makes individuals (slightly) richer. Hence, they value less an increase of the car travel costs, thereby requiring a higher toll to achieve the same level of traffic reduction.

\footnotetext{
${ }^{5}$ Note that our benchmark scenario differs from a zone toll of the London type. In London, one payment allows the vehicle to be used for as many journeys as the driver wishes in the charging zone. In our scenario, a fee is imposed on each single trip in the charging zone.

${ }^{6}$ In both scenarios, redistribution also concerns captive PT users - defined as PT users without a driver's license or access to a car. These commuters represent around 43\% of total PT users making home-to-work trips in Paris.
} 


\section{Results and discussion}

We present our results in two steps. First, we study the average individual welfare changes induced by the different scenarios. In doing this, we seek to compare the overall degree of political acceptability of different tolls. Then, we assess the distributional effects across different income groups for each scenario.

\subsection{Average compensating variations}

Table 5 describes the average compensating variations induced by the different scenarios as well as the percentage of winners in each scenario. We focus on the scenarios involving a $20 \%$ traffic reduction as the impact on average $c v$ of different reduction rates is easily predictable.

The most important result is that, whatever the scenario, the average compensating variation of motorists is significantly negative. In other words, motorists taken as a whole tend to lose when a toll is introduced. The percentage of winners is even zero for the Zone scenario which does not include exemptions.

This is not surprising given the values of travel time presented in Table 3. At most, they reach 11.4 euros per hour. This implies that, for instance, a toll of 2 euros per day would need to reduce per day travel times by 11 minutes just to compensate for the toll. This time saving is unlikely in a charging zone of 105 sq $\mathrm{km}$ where the duration of trips is necessarily limited (22 minutes on average for car trips inside Paris).

If average $c v s$ are all negative, the magnitude of the loss varies across scenarios. For instance, Residents induces lower losses than Zone (€0.81 versus €1.01). This is so because the exemption yields two opposite effects. On the one hand, residents pay less (€0.255 instead of $€ 2.55)$. On the other hand, this partial exemption requires increasing the toll to keep the same traffic reduction level, thereby rising individual losses for the rest of the population (€2.55 for 
Residents instead of $€ 1.70$ for Zone). Our simulations show that the former dominates the latter, probably because the proportion of residents among the motorists who stay on the road once the toll is introduced under the Zone scenario is quite high (around 50\%).

Conversely, the average losses induced by Inbound Cordon and Green are similar to the benchmark ( $€ 1.03$ and $€ 1.02$ versus $€ 1.01$ for Zone) suggesting that the two effects compensate each other.

Turning next to the scenarios PT funding and Uniform Redistribution, the recycling of revenues towards commuters obviously decreases losses. The two recycling scenarios produce similar results in terms of average loss (€0.68). To begin with, tolling is clearly politically risky as the proportion of gainers is low in most cases. Then, if reducing potential political opposition of motorists is crucial, redistributing revenues to commuters is obviously adequate.

\subsection{Distributional effects across income groups}

Having compared the average $c v$ induced by the different scenarios, we now consider equity issues by examining how the $c v$ varies across income groups.

\section{Traffic reduction}

Table 6 focuses on the Zone scenario and considers the influence of different levels of traffic reduction on equity. We express $c v s$ in euros per trip and in proportion of income.

Let us first discuss the value of $c v s$ expressed in euros per trip. Table 6 immediately shows that low-income motorists loose more than richer motorists when the reduction rate is low $(10 \%$ or 20\%). But the reverse is true for higher reduction rates.

In order to explain this result, recall first that high income motorists - who are also individuals with high value of time - tend to place more value on congestion reduction and are 
less affected by the toll's financial burden (because the marginal utility of income is decreasing). This is why, in theory, they would tend to lose less than low-income motorists when they keep using their car ex post. This scenario only applies to the motorists who continue to use their cars once the toll is introduced.

What about the income profile and $c v$ of those who switch to PT? Table 7 compares their $c v$ and income with those of the ex post motorists' group under the Zone scenario. We can see that they lose much less than the other group and that they have lower income.

To sum up, we have two opposite effects. On the one hand, the richest individuals lose less than the poorest within the group of motorists who continue to use their car. On the other hand motorists who shift to PT are poorer than the motorists staying on the road, and lose less. According to Table 6, the first effect dominates the second when motorists continuing to use their cars are numerous - that is, when tolling reduce the traffic by $10,20 \%$ - while the reverse is true for higher levels of traffic reduction (50\%). Under the $30 \%$ reduction scenario both effects compensate each other so that cvs do not change across income groups.

Finally, when considering $c v$ in percentage of income, Table 6 shows that low-income individuals lose more than richer individuals whatever the scenario. Therefore, all scenarios are regressive.

\section{Exemptions}

We now investigate the impact of different exemptions. Table 8 shows the difference between the average $c v$ under Inbound Cordon, Residents, and Green and the average $c v$ under Zone. Figures are given for the income group 1 which gathers the $20 \%$ of individuals with the lowest income. We focus on $c v$ in $€$ /trip as there is no reason why patterns would significantly change with $c v$ expressed in proportion to income. 
The ranking between the different scenarios is not ambiguous. The scenario Inbound Cordon is the worst option for low-income individuals. The scenario Residents is similar to Zone while Green makes low-income motorists slightly better off. In order to understand why this is, Table 8 displays the percentage of motorists who enjoy a rebate or an exemption in income group 1 as compared to the whole population. Under Cordon, the share of poor motorists travelling within Paris (7\%) is half that of the whole population (15\%). On the other hand, about $36 \%$ of motorists drive low CO2 emitting cars in income group 1 - a proportion slightly higher than in the whole population, while Residents is an intermediate case. This is consistent with the ranking given by Table 8 .

We complete the analysis of the influence of exemptions by examining how the level of losses varies with the level of income. Figure 1 and 2 shows $c v$ as a function of income for the motorists and the commuters respectively. Using this indicator, Green is again the best scenario for the poorest. Then, Zone is in intermediate position while Residents and Inbound Cordon are the less equitable options.

Note also that, except for Residents, the welfare losses are an increasing function of income for the whole population of commuters while it is generally the opposite within the motorists' group. The explanation is straightforward. Low-income individuals tend to use PT much more than high-income individuals: $70 \%$ of those in quintile 1 use PT, but only $37 \%$ of those in quintile 5.

\section{Recycling of toll revenues}

Until now, we have discussed scenarios in which revenues are not redistributed to commuters, meaning that recycling has no impacts on the distributional profile. Here, we consider the scenario where revenues are used to cut PT fares (PT Funding) and the scenario in which revenues are evenly redistributed to all commuters (Uniform Redistribution). 
Table 9 gathers the main figures. It shows that the two scenarios have the same distributional profile. This might be surprising as low-income commuters opt more frequently for the PT mode. Given this, one would expect smaller losses for them under the PT funding scenario which allocates all the revenues to PT. But this is not the end of the story. Reducing the cost of PT increases the incentives for motorists to withdraw their car. Therefore, the toll rate necessary for a $20 \%$ traffic reduction is smaller than without redistribution to $\mathrm{PT}^{7}$ Hence, motorists also gain, albeit indirectly, when the revenues are allocated to PT.

\section{Conclusion}

We have developed an econometric model to simulate the distributional effects of various urban road pricing scenarios in Paris. The methodology is based on a mode choice model that is nonlinear in income. This is particularly suitable for assessing distributional effects as it relaxes the assumption of constant marginal utility of income made in traditional models. Nevertheless, two methodological limits should be kept in mind when interpreting the results. First, we only deal with home-to-work trips. Second, we rely on a basic traffic model - a simple speed-flow relationship - to calculate the time reductions induced by tolling.

That being said, the analysis brings out four types of results. First, we show that motorists endure average welfare losses ranging from $€ 0.7$ to $€ 1.0$ per trip when a toll that induces a $20 \%$ traffic reduction is implemented. In other words, motorists taken as a whole tend to lose when a toll is introduced. This result is not surprising when one considers their values of travel time. They reach $€ 11.4$ per hour at the most, which would require a travel time reduction of around 11 minutes to outweigh a $€ 2$ toll, for example. For scenarios geographically limited to Paris, such large time savings are almost always impossible.

\footnotetext{
${ }^{7}$ According to our simulations, the toll is $€ 1.40$ under $P T$ funding as compared to $€ 1.70$ under Zone.
} 
Although all the scenarios imply welfare losses on average for motorists, those losses do not have the same magnitude. They are smaller when residents are partially exempted. Thus, the political acceptability of tolling could be improved with this exemption. On the other hand, an inbound cordon toll exempting those who make car trips within Paris generates the highest average loss.

Concerning the distributional effects of tolls across different income groups, conclusions primarily depend on whether the losses induced by tolling are measured in absolute terms, i.e., in euros per trip, or in relative terms, i.e., as a percentage of income. In relative terms, tolls are always more detrimental to low-income individuals, meaning that tolling is regressive.

In absolute terms, results are much less clear-cut. In fact, the distributional pattern depends crucially on the level of traffic reduction. When it is low (10\% or $20 \%)$, the poorest motorists lose more than the richest ones. But the reverse is true for higher reduction rates. The reason for this is that the motorists who switch to PT lose less and are poorer on average than the other motorists. As the size of this subpopulation increases with the level of traffic reduction, stringent tolls tend to be more favourable to low-income individuals.

Turning next to the impacts of various exemptions, an interesting result is that granting a rebate to low CO2 emission cars slightly improves the situation of low-income individuals relative to high-income individuals while the inbound cordon scenario has opposite effects. This is because motorists entering Paris have lower incomes. The distributional pattern of the scenario in which Paris residents only pay $10 \%$ of the toll is contrasted. Clearly, the poorest individuals lose more than the richest ones, because residents are far richer than suburban individuals. But they endure the same losses as under the reference scenario without exemption. 
When taking into account the allocation of toll revenues, we obtain the somewhat surprising result that there is no significant difference between a scenario which allocates receipts to PT users and a scenario which evenly distributes receipts to all commuters. One would expect PT funding to be more favourable to low-income individuals as motorists are significantly richer than PT users. However, allocating money to PT increases the incentives for motorists to withdraw their car. Therefore, for a given traffic reduction rate, the level of the toll is lower, implying indirect gains for motorists.

In our view, the major policy lesson of this analysis is that the design of the road pricing scheme and the level of traffic reduction strongly influence equity patterns. Note that the same is probably true for social efficiency. But this is out of the scope of the present paper.

\section{Acknowledgments}

We gratefully acknowledge financial support from the French Interministerial Task-Force on Climate Change (MIES). We are also grateful to the Ile-de-France Regional Directorate for the Equipment (DREIF) for the provision of data.

\section{References}

Dagsvik, J. K. and Karlström, A. (2005) Compensating Variation and Hicksian Choice Probabilities in Random Utility Models that are Nonlinear in Income. Review of Economics Studies, 72 (1), 57-76. 
Eliasson, J. and Mattsson, L.G. (2006) Equity Effects of Congestion Pricing, Transportation Research Part A, 40 (7), 602-20.

Franklin, J. P. (2006) The Equity Effects of Roadway Tolls: An Application of Hicksian Welfare Measures with Income Effects, paper presented at the 11th International Conference on Travel Behaviour Research, Kyoto, August 2006.

Jara-Díaz, S.R. and Videla, J. (1989) 'Detection of income effects in mode choice: theory and applications », Transportation Research Part B, 23 (6), pp 393-400.

McFadden, D. (1999) Computing willingness-to-pay in random utility models’ in J. Moore, R. Riezman, and J. Melvin (eds) Trade, Theory and Econometrics: Essays in Honour of John S. Chipman. London: Routledge.

Maruyama, T. and Sumalee, A. (2007), Efficiency and equity comparison of cordon- and areabased road pricing schemes using a trip-chain equilibrium model, Transportation Research Part A, 41, 655-671.

Raux, C. and Souche, M. (2004) The acceptability of urban road pricing, Journal of Transport Economics and Policy, 38(2), 191-216.

Safirova, E., Harrington, W., Nelson, P., Parry, I.W., Gillingham, K. and Mason, D. (2003) Welfare and Distributional Effects of Road Pricing Schemes for Metropolitan Washington DC, in Santos, G. (ed.) Road Pricing, Theory and Evidence, Elsevier Science. 
Santos, G. and Rojey, L. (2004) Distributional Impacts of Road Pricing: The Truth behind the Myth, Transportation, 31 (1), 21-42.

Teubel, U. (2000) The welfare effects and distributional impacts of road user charges on commuters: an empirical analysis of Dresden, International Journal of Transport Economics, 27(2), 231-54. 


\section{Appendix}

For a given individual trip, we calculate the new car travel time $T_{A}^{1}$ after the introduction of the toll with the formula:

$$
T_{A}^{1}=\left\{\begin{array}{l}
T_{A}{ }^{0}\left(\frac{S P E E D^{0}}{S P E E D^{1}}\right) \text { if the trip is exclusively made inside Paris } \\
T_{A}^{0}+\left(\frac{3,171}{v_{A}^{0}}\right)\left(\frac{S P E E D^{0}}{S P E E D^{1}}-1\right), \quad \text { otherwise }
\end{array}\right.
$$

with:

- $\quad S P E E D^{0}$ : the average car speed before the introduction of the toll in the slot during which the individual trip is made

- $\quad S P E E D^{1}$ : the average car speed after the introduction of the toll in the slot during which the trip is made. It is estimated using the speed-flow relationship.

- $T_{A}{ }^{0}$ : the travel time before the toll.

- $\quad v_{A}{ }^{0}$ : the individual speed before the toll

- $3,171 \mathrm{~m}$ is the average distance covered by motorists that travel exclusively in the charging zone.

The major assumption underlying the formulas for calculating $T_{A}{ }^{1}$ is that the individual speed increase rate is equal to the increase of the average speed in the time slot. That is, $v_{A}^{0} / v_{A}^{1}=S P E E D^{0} / S P E E D^{1}$

Under this assumption, deriving $T_{A}^{1}$ for the trips made inside Paris is straightforward. It is less obvious for the other trips. Let $d$ denote the total trip distance and $d^{P}$ the distance made in Paris. As previously stated, we assume that $d^{P}=3,171 \mathrm{~m}$. Then, we have 


$$
T_{A}^{1}=\frac{\left(d-d^{P}\right)}{v_{A}^{0}}+\frac{d^{P}}{v_{A}^{1}}
$$

Rearranging $v_{A}^{0} / v_{A}^{1}=S P E E D^{0} / S P E E D^{1}$ and substituting in (A.1) yields the formula.

Sensitivity analysis shows that our results are pretty robust to changes in distances covered in the charging zone. For instance, the assumption that motorists travelling partially in the charging zone - those whose origin or destination is outside the zone - cover a distance equal to the average of distances covered by motorists that travel exclusively in the charging zone (3,171 meters) is robust. Doubling this distance (6,342 meters) - which means doubling the distance for which motorists enjoy travel time savings - does not modify the final distributional patterns significantly.

Finally, Table A1 gives the average travel time reduction and the average speed variation for the different toll scenarios. The table only considers motorists driving before and after the toll is introduced.

Table A1: Travel time reduction and speed increase for the nine scenarios

\begin{tabular}{|l|c|cc|c|c|c|}
\hline Scenario & $\begin{array}{c}\text { Avg. initial } \\
\text { travel time }\end{array}$ & \multicolumn{2}{|c|}{$\begin{array}{c}\text { Avg. travel time } \\
\text { reduction induced by } \\
\text { tolling }\end{array}$} & \multicolumn{2}{|c|}{$\begin{array}{c}\text { Avg. } \\
\text { initial } \\
\text { speed }\end{array}$} & \multicolumn{2}{|c|}{$\begin{array}{c}\text { Avg. speed increase } \\
\text { induced by tolling }\end{array}$} \\
\hline & minutes & minutes & $\%$ & $\mathrm{~km} / \mathrm{h}$ & $\mathrm{km} / \mathrm{h}$ & $\%$ \\
\hline Zone 20\% & 36.2 & -1.9 & $-5 \%$ & 16.3 & 1.0 & $6 \%$ \\
Zone 10\% & 37.3 & -0.9 & $-2 \%$ & 16.1 & 0.4 & $3 \%$ \\
Zone 30\% & 35.6 & -2.9 & $-8 \%$ & 16.4 & 1.5 & $9 \%$ \\
Zone 50\% & 33.3 & -4.8 & $-14 \%$ & 16.1 & 3.6 & $23 \%$ \\
Inbound Cordon & 35.2 & -1.9 & $-6 \%$ & 15.8 & 1.0 & $6 \%$ \\
Residents & 35.6 & -2.0 & $-6 \%$ & 15.6 & 1.0 & $6 \%$ \\
Green & 36.6 & -1.9 & $-5 \%$ & 16.3 & 1.0 & $6 \%$ \\
PT funding & 36.2 & -1.9 & $-5 \%$ & 16.3 & 1.0 & $6 \%$ \\
Uniform & 36.2 & -1.9 & $-5 \%$ & 16.3 & 1.0 & $6 \%$ \\
redistribution & & & & & & \\
\hline
\end{tabular}


Figure 1: Average $c v$ of motorists (€/trip) by income group under Zone, Inbound Cordon, Residents and Green as compared to income group 1 (Income group 1 = Base 0)

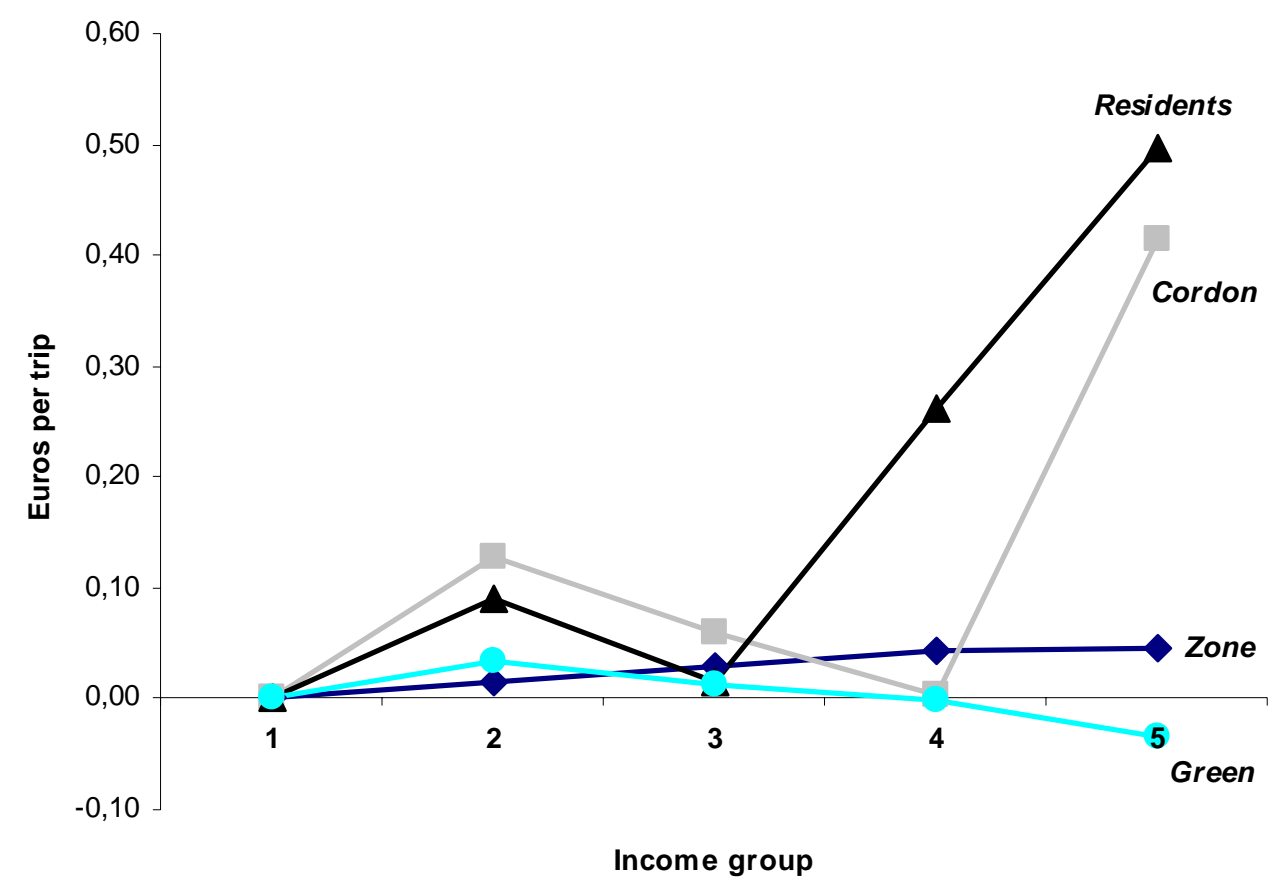


Figure 2: Average $c v$ of commuters (€/trip) by income group under Zone, Inbound Cordon, Residents and Green as compared to income group 1 (Income group $1=$ Base 0$)$

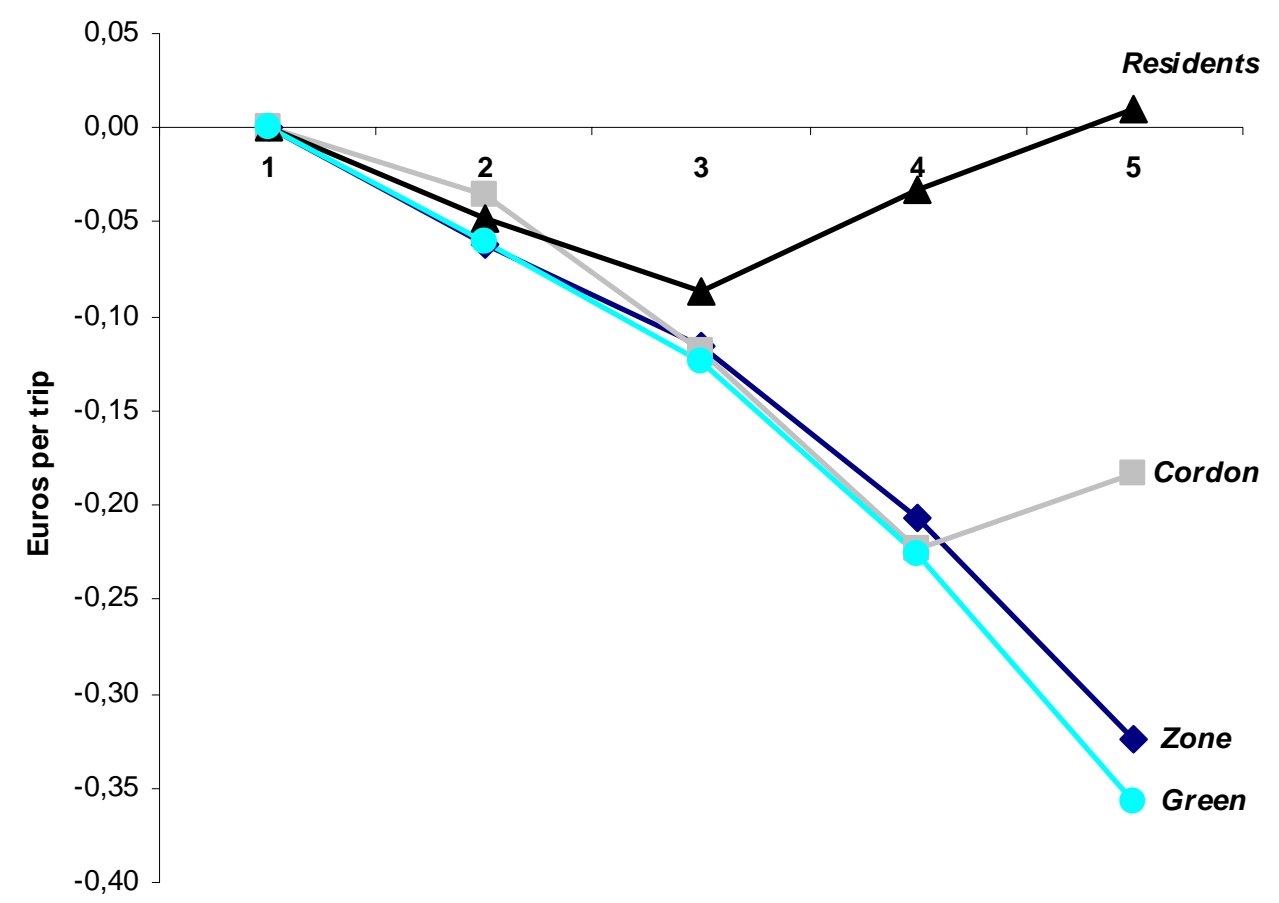

Income group 
Table 1: Descriptive statistics

\begin{tabular}{|c|c|c|c|c|}
\hline Variable & Definition & $\begin{array}{c}\text { Number of } \\
\text { observations }\end{array}$ & Mean & $\begin{array}{l}\text { Standard } \\
\text { Deviation }\end{array}$ \\
\hline A & $\begin{array}{l}=1 \text { if a private car is used. } 0 \text { if } \\
\text { PT is used }\end{array}$ & 1030 & 0.29 & 0.45 \\
\hline$T_{B}-T_{A}^{0}$ & $\begin{array}{l}\text { Time differential between PT } \\
\text { and car (minutes) }\end{array}$ & 1030 & 3.79 & 20.38 \\
\hline$C_{B}$ & $\begin{array}{l}\text { Monetary cost of a PT trip } \\
\text { (euros) })^{\mathrm{a}}\end{array}$ & 1030 & 0.67 & 0.22 \\
\hline$C_{A}^{0}$ & $\begin{array}{l}\text { Monetary cost of a private car } \\
\text { trip (euros) }\end{array}$ & 1030 & 3.77 & 2.53 \\
\hline$y$ & $\begin{array}{l}\text { Daily household income per } \\
\text { capitac (euros) }^{\mathrm{c}} \text { (e) }\end{array}$ & 1030 & 104.38 & 58.86 \\
\hline$D C$ & $\sqrt{y-C_{B}}-\sqrt{y-C_{A}^{0}}$ & 1030 & 0.18 & 0.17 \\
\hline FEMALE & $\begin{array}{l}=1 \text { if the individual is a } \\
\text { woman. } 0 \text { otherwise }\end{array}$ & 1030 & 0.45 & 0.50 \\
\hline FREE_PARK & $\begin{array}{l}=1 \text { if the individual gets a car } \\
\text { park for free at her place of } \\
\text { work, } 0 \text { otherwise }\end{array}$ & 1030 & 0.41 & 0.49 \\
\hline$N B \_C A R S$ & $\begin{array}{l}\text { Number of cars in the } \\
\text { household }\end{array}$ & 1030 & 1.41 & 0.60 \\
\hline$T W O \_C A R S$ & $\begin{array}{l}=1 \text { if the individual belongs to } \\
\text { a household that owns two cars } \\
\text { or more, } 0 \text { otherwise }\end{array}$ & 1030 & 0.35 & 0.48 \\
\hline$T W O \_K I D S$ & $\begin{array}{l}=1 \text { if the individual belongs to } \\
\text { a household with two children } \\
\text { or more, } 0 \text { otherwise }\end{array}$ & 1030 & 0.19 & 0.40 \\
\hline RESIDENT & $\begin{array}{l}=1 \text { if the individual lives in } \\
\text { Paris, } 0 \text { otherwise }\end{array}$ & 1030 & 0.27 & 0.44 \\
\hline $\mathrm{CO} 2$ & $\begin{array}{l}\text { CO2 emissions of the car used }{ }^{\mathrm{d}} \\
\text { (g/Km) (specific to car users) }\end{array}$ & 296 & 187.92 & 11.23 \\
\hline
\end{tabular}

${ }^{\mathrm{a}}$ In order to estimate $\mathrm{C}_{\mathrm{B}}$, we use season ticket prices in force in July 2001.

${ }^{\mathrm{b}}$ In order to estimate $\mathrm{C}_{\mathrm{A}}$, we use an average kilometric cost of $€ 0.269$ per kilometre. This average cost is computed by the Ile-de-France public transport regulator (STIF) for 2001 and includes fuel, maintenance and parking costs.

${ }^{c}$ Ideally, it would have been better to use income available once the accommodation spending have been paid rather than income per capita, as an evident relationship exists between accommodation spending and transport spending. Unfortunately, this information is not available.

d CO2 emissions are not recorded directly in the Global Transport Survey. Details on the methodology and on the additional data references used to estimate $\mathrm{CO} 2$ emissions are available on request. 
Table 2: Results of the mode choice estimation: $\mathbf{P}_{\mathrm{A}}$

\begin{tabular}{|lccl|}
\hline & Coefficient & Std. Err. & p-value \\
\hline$T_{B}-T_{A}^{0}$ & .019396 & .0024988 & 0.000 \\
DC & -3.000992 & .3684194 & 0.000 \\
FEMALE & -.7882079 & .1771549 & 0.000 \\
FREE_PARK & 1.818979 & .1723604 & 0.000 \\
TWO_CARS & 1.029045 & .1754081 & 0.000 \\
TWO_KIDS & .54412 & .2125591 & 0.010 \\
Constant & -1.310106 & .1962443 & 0.000 \\
\hline 1030 observations & & \\
Log likelihood $=-435.35$ & & \\
McFadden pseudo R2 $=0.30$ & & \\
\hline
\end{tabular}

Table 3: Values of time for different groups of travellers (euros per hour)

\begin{tabular}{|l|c|ccccc|}
\hline & & \multicolumn{5}{|c|}{ Income group } \\
& All & 1 & 2 & 3 & 4 & 5 \\
\hline Car & $7.9 € / h$ & $5.0 € / h$ & $6.7 € / h$ & $7.9 € / h$ & $10.0 € / h$ & $11.4 € / h$ \\
PT & $8.2 € / h$ & $6.0 € / h$ & $7.2 € / h$ & $8.0 € / h$ & $9.9 € / h$ & $11.4 € / h$ \\
\hline
\end{tabular}


Table 4: Description of the nine scenarios

\begin{tabular}{|c|c|c|c|c|c|}
\hline Scenario name & Definition & $\begin{array}{c}\text { Redistribution } \\
\text { of revenues to } \\
\text { travellers } \\
\end{array}$ & $\begin{array}{l}\% \text { traffic } \\
\text { charged }\end{array}$ & $\begin{array}{l}\text { Traffic } \\
\text { reduction } \\
\text { rate } \\
\end{array}$ & $\begin{array}{l}\text { Toll level } \\
\text { (per trip) }\end{array}$ \\
\hline Zone & $\begin{array}{l}\text { Traffic in or through } \\
\text { Paris is charged with a } \\
\text { uniform charge }\end{array}$ & No & $100 \%$ & $\begin{array}{l}10 \% \\
20 \% \\
30 \% \\
50 \%\end{array}$ & $\begin{array}{l}€ 0.70 \\
€ 1.70 \\
€ 2.55 \\
€ 4.25\end{array}$ \\
\hline $\begin{array}{l}\text { Inbound } \\
\text { Cordon }\end{array}$ & $\begin{array}{l}\text { Traffic entering Paris } \\
\text { is charged }\end{array}$ & No & $85 \%$ & $20 \%$ & $€ 2.20$ \\
\hline Residents & $\begin{array}{l}\text { Zone }+ \text { a } 90 \% \text { rebate } \\
\text { for Paris residents }\end{array}$ & No & $\begin{array}{l}100 \% \\
\text { (27\% of } \\
\text { residents) }\end{array}$ & $20 \%$ & $€ 2.55$ \\
\hline Green & $\begin{array}{l}\text { Zone }+ \text { a } 50 \% \text { rebate } \\
\text { for cars emitting less } \\
\text { than } 180 \mathrm{~g} \text { CO2 per km }\end{array}$ & No & $\begin{array}{c}100 \% \\
\text { (31\% of low } \\
\text { CO2 emitting } \\
\text { cars) } \\
\end{array}$ & $20 \%$ & $€ 2.05$ \\
\hline PT funding & $\begin{array}{l}\text { Zone }+ \text { net revenues } \\
\text { used to cut PT fares }\end{array}$ & Yes & $100 \%$ & $20 \%$ & $€ 1.40$ \\
\hline $\begin{array}{l}\text { Uniform } \\
\text { redistribution }\end{array}$ & $\begin{array}{l}\text { Zone }+ \text { net revenues } \\
\text { redistributed evenly to } \\
\text { all commuters }\end{array}$ & Yes & $100 \%$ & $20 \%$ & $€ 1.75$ \\
\hline
\end{tabular}

Table 5: Average compensating variations (€/trip) and proportion of gainers under six toll scenarios inducing a $20 \%$ traffic reduction

\begin{tabular}{|l|cc|cc|}
\hline Scenario & \multicolumn{2}{|c|}{ Motorists only $^{\mathrm{a}}$} & \multicolumn{2}{c|}{ All commuters } \\
& Avg. $c v$ & $\begin{array}{c}\mathrm{b} \text { of trips } \\
\text { with } c v>0\end{array}$ & Avg. $c v$ & $\begin{array}{c}\% \text { of trips } \\
\text { with } c v>0\end{array}$ \\
\hline $\begin{array}{l}\text { Zone } \\
\begin{array}{l}\text { Inbound } \\
\text { Cordon }\end{array}\end{array}$ & $€-1.01$ & $0 \%$ & $€-0.35$ & $0 \%$ \\
Residents & $€-1.03$ & $20 \%$ & $€-0.36$ & $11 \%$ \\
$\begin{array}{l}\text { Green } \\
\text { PT funding }\end{array}$ & $€-1.02$ & $25 \%$ & $€-0.30$ & $13 \%$ \\
$\begin{array}{l}\text { Uniform } \\
\text { redistribution }\end{array}$ & $€-0.68$ & $0 \%$ & $€-0.36$ & $0 \%$ \\
\hline
\end{tabular}

\footnotetext{
a "Motorists only" refer to those travelling by car before the toll has been introduced whatever their mode choice after tolling.

b “All commuters” refer to all the members of our sample (i.e., motorists and non-captive PT users) plus captive PT users (i.e., those without a driver's license or access to a car). A null cv is assigned to the latter.
} 
Table 6: Average $c v(€ /$ trip) by income group under different levels of traffic reduction (Zone scenario)

\begin{tabular}{|c|c|c|c|c|c|}
\hline \multirow[t]{2}{*}{ Traffic reduction } & \multicolumn{5}{|c|}{ Income groups } \\
\hline & 1 & 2 & 3 & 4 & 5 \\
\hline \multicolumn{6}{|c|}{$c v$ in euros per trip } \\
\hline \multicolumn{6}{|l|}{$10 \%(€ 0.70)$} \\
\hline Motorists only & -0.48 & -0.43 & -0.42 & -0.41 & -0.40 \\
\hline All commuters & -0.11 & -0.12 & -0.15 & -0.18 & -0.22 \\
\hline \multicolumn{6}{|l|}{$20 \%(€ 1.70)$} \\
\hline Motorists only & -1.04 & -1.03 & -1.01 & -1.00 & -1.00 \\
\hline All commuters & -0.23 & -0.29 & -0.34 & -0.43 & -0.55 \\
\hline \multicolumn{6}{|l|}{$30 \%(€ 2.55)$} \\
\hline Motorists only & -1.48 & -1.48 & -1.47 & -1.47 & -1.49 \\
\hline All commuters & -0.31 & -0.41 & -0.49 & -0.63 & -0.82 \\
\hline \multicolumn{6}{|l|}{$50 \%(€ 4.25)$} \\
\hline Motorists only & -2.09 & -2.25 & -2.25 & -2.30 & -2.40 \\
\hline All commuters & -0.44 & -0.60 & -0.74 & -0.97 & -1.30 \\
\hline \multicolumn{6}{|c|}{$c v$ in proportion to income $(\times 1,000)$} \\
\hline \multicolumn{6}{|l|}{$10 \%(€ 0.70)$} \\
\hline Motorists only & -0.64 & -0.31 & -0.24 & -0.17 & -0.10 \\
\hline All commuters & -0.14 & -0.09 & -0.08 & -0.07 & -0.05 \\
\hline \multicolumn{6}{|l|}{$20 \%(€ 1.70)$} \\
\hline Motorists only & -1.38 & -0.74 & -0.56 & -0.40 & -0.24 \\
\hline All commuters & -0.30 & -0.21 & -0.19 & -0.17 & -0.14 \\
\hline \multicolumn{6}{|l|}{$30 \%(€ 2.55)$} \\
\hline Motorists only & -1.92 & -1.06 & -0.82 & -0.59 & -0.36 \\
\hline All commuters & -0.41 & -0.30 & -0.27 & -0.25 & -0.20 \\
\hline \multicolumn{6}{|l|}{$50 \%(€ 4.25)$} \\
\hline Motorists only & -2.56 & -1.61 & -1.25 & -0.92 & -0.57 \\
\hline All commuters & -0.53 & -0.43 & -0.41 & -0.39 & -0.32 \\
\hline
\end{tabular}

NB: "Motorists only" refer to those travelling by car before the toll has been introduced whatever their mode choice after tolling. "All commuters" refer to all the members of our sample (i.e., motorists and non-captive PT users) plus captive PT users (i.e., those without a driver's license or access to a car). A null cv is assigned to the latter. 
Table 7: Average $c v$ and average income per capita of two groups of motorists (Zone scenario, traffic reduction: $20 \%$ )

\begin{tabular}{|lcc|}
\hline & Avg. $c v(€ /$ trip) & $\begin{array}{r}\text { Avg. monthly income } \\
\text { per capita (€) }\end{array}$ \\
\hline $\begin{array}{l}\text { Motorists staying on the road after the } \\
\text { introduction of the toll }\end{array}$ & $€-1.09$ & $€ 2,733$ \\
Motorists switching to PT & $€-0.71$ & $€ 1,843$ \\
\hline
\end{tabular}

Table 8: Difference between the average $c v$ under Inbound Cordon, Residents and Green and the average $c v$ under Zone (€/trip) in income group 1 and percentage of exempted motorists

\begin{tabular}{|c|c|c|c|}
\hline & \multirow{2}{*}{$\begin{array}{l}\text { Avg. } c v \text { under alternative scenarios } \\
\text { minus avg. } c v \text { under Zone in income } \\
\text { group } 1(€ / \text { trip) }\end{array}$} & \multicolumn{2}{|c|}{$\%$ of exempted motorists } \\
\hline & & Income group 1 & All \\
\hline \multicolumn{4}{|l|}{ Inbound Cordon } \\
\hline Motorists only & -0.15 & $7 \%$ & $15 \%$ \\
\hline All commuters & -0.05 & & \\
\hline \multicolumn{4}{|l|}{ Residents } \\
\hline Motorists only & 0.00 & $16 \%$ & $27 \%$ \\
\hline All commuters & 0.00 & & \\
\hline \multicolumn{4}{|l|}{ Green } \\
\hline Motorists only & 0.03 & $36 \%$ & $31 \%$ \\
\hline All commuters & 0.01 & & \\
\hline
\end{tabular}

NB: "Motorists only" refer to those travelling by car before the toll has been introduced whatever their mode choice after tolling. "All commuters" refer to all the members of our sample (i.e., motorists and non-captive PT users) plus captive PT users (i.e., those without a driver’s license or access to a car). A null cv is assigned to the latter. 
Table 9: Average cv (€/trip) under PT Funding and Uniform Redistribution by income groups

\begin{tabular}{|c|c|c|c|c|}
\hline \multirow[b]{2}{*}{ Quintile } & \multicolumn{2}{|c|}{ PT Funding } & \multicolumn{2}{|c|}{ Uniform Redistribution } \\
\hline & Motorists only ${ }^{\mathrm{a}}$ & All commuters ${ }^{b}$ & Motorists only ${ }^{a}$ & All commuters ${ }^{b}$ \\
\hline 1 & -0.71 & 0.12 & -0.71 & 0.12 \\
\hline 2 & -0.69 & 0.06 & -0.69 & 0.06 \\
\hline 3 & -0.68 & 0.00 & -0.68 & 0.00 \\
\hline 4 & -0.67 & -0.09 & -0.67 & -0.09 \\
\hline 5 & -0.67 & -0.22 & -0.67 & -0.21 \\
\hline All & -0.68 & -0.01 & -0.68 & -0.01 \\
\hline
\end{tabular}

a "Motorists only" refer to those travelling by car before the toll has been introduced whatever their mode choice after tolling.

b "All commuters" refer to all the members of our sample (i.e., motorists and non-captive PT users) plus captive PT users (i.e., those without a driver's license or access to a car). A null cv is assigned to the latter. 